\title{
NOTICIAS
}

\section{Doctor JW Lee Director General electo Organización Mundial de la Salud}

Alocución ante la $56^{a}$ Asamblea Mundial de la Salud. Ginebra, 21 de mayo de 2003

Señor Presidente, señoras y señores ministros, distinguidos delegados, señoras y señores:

$\mathrm{Al}$ elegirme como primer Director General de la Organización Mundial de la Salud (OMS) en este nuevo milenio, ustedes me han encomendado una responsabilidad muy grande.

La responsabilidad no sólo de proseguir la labor de mis distinguidos predecesores, sino también de lograr que la OMS pueda responder a las demandas cada vez más importantes a las que ha de dar respuesta.

Este desafío requiere un alto nivel de conocimientos, así como la buena voluntad y la firme determinación de cada uno de nosotros. Para afrontarlo también será necesario actuar con sensibilidad política, disponer de competencias técnicas y tener una visión ética.

Hoy me referiré brevemente a los principales valores que deben guiarnos en los próximos cinco años, así como a la situación sanitaria mundial y a la manera en que debemos afrontar los actuales desafíos en materia de salud.
Actualmente, el mundo necesita que se ejerza un liderazgo para orientar los esfuerzos encaminados a garantizar la seguridad contra la propagación de las enfermedades infecciosas y que se haga justicia a las personas más afectadas por las enfermedades de la pobreza. Precisamente, el sistema de las Naciones Unidas se fundó para defender estos dos principios de seguridad y justicia, que son interdependientes. Los dirigentes mundiales que redactaron la Carta de las Naciones Unidas comprendieron que la paz y la seguridad dependían de la creación de lo que llamaron "condiciones bajo las cuales pueda [...] mantenerse la justicia".

La Constitución de la OMS, firmada en 1946, retoma este principio que, si vale para la política mundial, también ha de aplicarse a la salud. La Organización tiene una misión amplia: trabajar para garantizar el goce del grado máximo de salud que se pueda lograr a "todo ser humano sin distinción de raza, religión, ideología política o condición económica o social". Nuestra Constitución nos impone un compromiso solidario y nos advierte que "la desigualdad de los diversos países en lo relativo al fomento de la salud y al control de las enfermedades" es un "peligro común" para todos los pueblos. No se trata de compromisos ingenuos. Cuando se formularon, acababa de concluir la guerra más destructiva que el mundo había conocido hasta entonces.

Hoy más que nunca es evidente que nuestra labor debe guiarse por los valores de la Carta de las Naciones Unidas y de la Constitución de la OMS.

La situación sanitaria mundial ha mejorado en muchos aspectos desde que se fundó la OMS hace 55 años. Hemos asistido a logros históricos, como la erradicación de la viruela, así como a reducciones considerables en la mortalidad infantil y al notable incremento de la longevidad en muchos países.

Pero existe un fuerte contraste entre estos éxitos y los graves problemas sanitarios que aún quedan por resolver y el sufrimiento de millones de personas que todavía no tienen acceso a los beneficios del progreso médico y científico.

Se siguen propagando graves infecciones mortíferas. En algunos países la pandemia del VIH/SIDA está anulando decenios de progresos en el aumento de la esperanza de vida: en las zonas más afectadas el SIDA puede llegar a matar a $25 \%$ de los adultos en los próximos 10 años. En parte debido a su combinación con el VIH, los progresos en la lucha contra la tuberculosis siguen siendo lentos. Cada año dos millones de personas mueren de tuberculosis. Por su parte, el paludismo provoca 3000 muertes diarias, principalmente de niños. 
También nos enfrentamos con nuevos problemas graves. El brote de SRAS pone de relieve la vulnerabilidad del mundo a las nuevas infecciones. Hace 10 días estuve en Beijing para analizar la situación con el gobierno de China. Pude comprobar que se están adoptando medidas enérgicas para luchar contra el SRAS. También constaté la urgente necesidad de reforzar la vigilancia de la morbilidad y los mecanismos de respuesta a escala local, nacional y mundial.

Al mismo tiempo, aumenta el número de víctimas de enfermedades no transmisibles. En conjunto, estas enfermedades representaron más de $45 \%$ de la carga de morbilidad mundial en 2001. Se prevé que este porcentaje aumentará. Somos conscientes de los problemas que aún quedan por resolver en relación con la salud de la mujer, incluida la salud materna. Durante el último decenio se han hecho escasos progresos en la reducción de las tasas de mortalidad materna. También se plantean problemas muy graves en la esfera de la salud mental.

Detrás de estas cifras están las dificultades con que tropiezan los sistemas de salud. Muchos países se enfrentan con graves carencias en materia de infraestructura, tecnologías médicas y recursos humanos para la salud. Las inversiones en sistemas sanitarios en las regiones en desarrollo siguen siendo insuficientes. Los países, los donantes y los organismos internacionales deben elaborar una respuesta coherente y efectiva.

Como resultado de estas tendencias, siguen ampliándose las desigualdades sanitarias en el mundo. Consideremos dos casos extremos. Una niña nacida en el Japón en 2002 tiene posibilidades razonables de vivir hasta el siglo XXII. Un niño nacido en el Afganistán ese mismo año tiene $25 \%$ de posibilidades de morir antes de los cinco años de edad.
La esperanza de vida media en algunos países de altos ingresos es de casi 80 años. Sin embargo, en algunas zonas del Africa subsahariana, el VIH/SIDA y otras amenazas sanitarias han reducido la esperanza de vida a 40 años o menos. Una sociedad mundializada en la que existen desigualdades tan agudas no es aceptable ni viable.

La cuestión de la equidad tiene un significado especial para mí, que vengo de Corea. Cuando era un muchacho, mi país se encontraba empobrecido y desgarrado por la guerra. Nuestro pueblo ha conocido los mismos padecimientos que muchos otros países pobres, tanto en el pasado como en el presente. Los coreanos de mi generación no hemos olvidado las lecciones de aquella época. Sabemos lo que significan los conflictos, la pobreza y la difusión de las enfermedades. En esta experiencia formativa se basa mi determinación de hacer hincapié en las necesidades sanitarias de los desfavorecidos.

\section{Señor Presidente:}

Permítame referirme ahora a la forma en que la OMS y sus asociados han de abordar los problemas sanitarios mundiales en los próximos años. Las principales orientaciones de nuestra labor ya están claras.

Hace 25 años, la Declaración de Alma-Ata proclamó la meta de "salud para todos en el año 2000", que debía alcanzarse mediante el fortalecimiento de los sistemas de atención primaria de salud. No podemos retrasar el reloj de Alma-Ata. Pero debemos renovar el compromiso fundamental de lograr la equidad expresado en la fórmula "salud para todos". La OMS debe trabajar para convertir este ideal en resultados medibles estableciendo un nuevo tipo de relación con los Estados Miembros.

La clave de la labor de la OMS en los próximos años será un nuevo compromiso para conseguir resultados en los países. De aquí a cinco años, nuestras operaciones se habrán centrado mucho más en los países. Estaremos "más cerca de la base" e intensificaremos nuestra colaboración con las autoridades sanitarias nacionales para dar respuesta a sus objetivos prioritarios en materia de salud. Nos centraremos en el logro de objetivos alcanzables en esferas en las que la OMS puede proporcionar conocimientos técnicos y recursos.

Nuestro colega de la OMS, el doctor Carlo Urbani, ha mostrado lo que puede significar esa orientación para el logro de resultados en los países. El doctor Urbani murió de síndrome respiratorio agudo severo (SRAS) el pasado 29 de marzo. Fue el primero en reconocer la importancia de esta nueva enfermedad y trató los primeros casos en Hanoi. Junto con otros médicos y científicos de la OMS dio la alerta mundial que permitió desplegar esfuerzos para contener la infección y salvar muchas vidas.

Poco antes de que el doctor Urbani se enfermase, su mujer le expresó su preocupación por los peligros a que se exponía. El doctor Urbani le contestó: "si no puedo trabajar en este tipo de situaciones, ¿para qué estoy aquí? ¿Para responder a los mensajes electrónicos y dedicarme al papeleo?"

Carlo Urbani dio lo mejor de sí a la OMS: no se dedicó al papeleo, sino a impulsar la lucha contra la pobreza y las enfermedades.

Hoy tenemos el honor de que nos acompañe la señora Giuliana Chiorrini, esposa del doctor Urbani. Le ruego a ella y a su familia que acepten la expresión de nuestro pesar y de nuestra profunda gratitud por la labor y la vida de su esposo.

Señor Presidente:

Mi visión de la OMS se basa en el compromiso de lograr resultados en 
los países. Tal como lo concibo, este compromiso tiene cinco consecuencias principales. Permítame que me refiera brevemente al amplio alcance de cada una de estas consecuencias para nuestra labor conjunta.

La primera consecuencia es la búsqueda activa del logro de objetivos sanitarios medibles, incluidos los Objetivos de Desarrollo del Milenio adoptados en septiembre de 2000 en la Cumbre del Milenio de las Naciones Unidas. En ellos se establecen metas claras para los países en materia de nutrición, acceso al agua salubre, salud materno infantil, lucha contra las enfermedades infecciosas y acceso a los medicamentos esenciales. Estos objetivos son elementos estratégicos clave de un amplio programa sanitario basado en el legado de Alma-Ata.

Un elemento central de este programa debe ser la intensificación de la lucha contra el VIH/SIDA. Mediante la colaboración con el ONUSIDA, el Fondo Mundial, los Estados Miembros, la sociedad civil y otros interesados, velaré por que la OMS desempeñe una función de liderazgo en el logro de la ambiciosa meta de ampliar el acceso a la terapia antirretrovírica a tres millones de personas de los países en desarrollo para 2005. La promoción de esta terapia debe ir acompañada de una intensificación de los esfuerzos encaminados a prevenir el VIH. Utilizaremos la prestación de servicios de lucha contra el VIH/SIDA para fortalecer los sistemas sanitarios. Colaboraremos con diversos asociados para intensificar la colaboración de las comunidades en la prevención, atención y tratamiento del VIH/ SIDA.

Asimismo, promoveremos el logro de otras metas sanitarias. Durante ocho años he dirigido campañas contra la poliomielitis: durante cuatro años en la Región del Pacífico Occidental y posteriormente en la sede. Me comprometo a lograr la erradicación de esta enfermedad antes de que concluya mi mandato de Director General.

El compromiso de lograr resultados tiene una segunda consecuencia para nuestra labor conjunta, que consiste en destinar más recursos a los países. La descentralización de la labor de la OMS es una medida que permitirá prestar servicios más eficientes a los países. Esta descentralización se llevará a cabo en los casos en que sea un medio para promover el logro de resultados positivos sobre el terreno. Se trata de aplicar nuestra fuerza institucional -la de toda la OMS- allí donde pueda ser más útil para atender las necesidades de los países.

Esto guarda estrecha relación con mi tercera consigna: la eficiencia. En pocas palabras, propongo introducir cambios concretos en cuanto al establecimiento de prioridades y a la adopción de medidas encaminadas a reducir los costos. Para aumentar la eficiencia es necesario utilizar mejor las nuevas tecnologías. Hemos hecho progresos en materia de tecnología de la información pero aún queda mucho por hacer. Propongo acelerar las inversiones en la esfera de la tecnología de la información y, concretamente, en la infraestructura de comunicaciones que vincula a las oficinas en los países con las regiones y la sede.

La cuarta consecuencia es la necesidad de hacer hincapié en la rendición de cuentas. Como Director General me propongo fortalecer sustancialmente la función de auditoría en la OMS.

Ahora bien, considero que la rendición de cuentas no se limita a las cuestiones financieras, sino que también abarca la eficiencia de nuestras contribuciones al logro de resultados sanitarios.

De una manera más general, toda la labor que llevan a cabo los países debe estar orientada sobre la base de datos sanitarios más fiables y oportunos. En consecuencia, el mejoramiento de la vigilancia sanitaria y de la gestión de datos en el ámbito mundial será un objetivo fundamental en la OMS en los próximos cinco años.

Dirigiré a la OMS y a sus asociados para llevar a cabo una expansión y un fortalecimiento en gran escala de la Red Mundial de Alerta y Respuesta ante Brotes Epidémicos. El SRAS es la primera nueva enfermedad que representa una amenaza en el siglo XXI, pero no será la última. Completaremos el establecimiento de los mecanismos de control del SRAS y fortaleceremos nuestras defensas contra la próxima infección mortífera. El 90\% de los recursos se destinarán a ampliar la capacidad de vigilancia de la morbilidad en los países y las regiones. Ya se han anunciado compromisos de contribuciones sustanciales y acogemos con sumo beneplácito el anuncio reciente de los Estados Unidos de América de que prestará su apoyo en esta esfera.

También ampliaremos y mejoraremos los sistemas de medición de la salud, con especial hincapié en la ampliación de la capacidad en los países. Es necesario disponer de sistemas racionalizados de medición de la salud para poder hacer un seguimiento de los progresos en el logro de las metas sanitarias y mejorar la responsabilización mutua entre los países, los donantes y los organismos internacionales.

Mi quinta y última consigna para los próximos años consistirá en fortalecer los recursos humanos tanto dentro como fuera de la Organización.

Estoy elaborando planes para crear posibilidades de carrera que aclaren las expectativas institucionales y permitan que los funcionarios de la OMS puedan tener un desarro- 
llo profesional en el curso de su carrera en la Organización. Asimismo, estoy firmemente decidido a lograr que la dotación de personal del cuadro orgánico de la OMS refleje un mayor equilibrio entre los géneros y responda mejor a la diversidad de nuestros Estados Miembros.

Asimismo -actuando hacia fuera-debemos ayudar a los países para que aborden el desafío de dotarse de suficiente recursos humanos para la salud. Utilizaré los conocimientos especializados y la experiencia de la OMS para elaborar soluciones que permitan resolver los problemas de crisis de personal con que tropiezan muchos sistemas sanitarios.

Señor Presidente:

$\mathrm{Al}$ iniciar estas observaciones recordé los valores básicos de la seguridad y la justicia, que son inseparables. Me referí a dos graves problemas que plantea actualmente la situación sanitaria mundial. Y expliqué cuál es, a mi entender, la forma en que la OMS debe desempeñar su papel rector para abordar estos problemas, a saber: asumiendo un nuevo compromiso para realizar en los países actividades orientadas a los resultados centrándose en cinco temas fundamentales.

En mi trabajo en la OMS y en el ejercicio de la medicina antes de incorporarme a la Organización, aprendí que es muy importante saber escuchar. Deseo que la OMS se convierta en una organización que escuche más y ponga mayor hincapié en la comunicación abierta. Yo mismo me dedicaré activamente a modelar esta actitud. El intercambio de ideas será fundamental en los próximos meses. Pero en definitiva su eficacia se verá en la práctica. Unamos nuestras fuerzas para acometer la labor que tenemos por delante.

Muchas gracias.

\section{OMS: el camino hacia adelante. Entrevista con Lee Jong-Wook}

El nuevo Director General de la OMS abriga grandes aspiraciones para mejorar la salud mundial

1. El síndrome respiratorio agudo severo, o SRAS, ha protagonizado los titulares últimamente. ¿Cuál ha sido el papel de la Organización Mundial de la Salud (OMS) y qué hemos aprendido a raíz de esta epidemia?

El SRAS ha confirmado el liderazgo de la OMS en la protección de la comunidad internacional contra las amenazas emergentes para la salud. Desde que se declaró el brote, la OMS ha sido el principal productor mundial de información sobre el SRAS y ha actualizado diariamente dicha información en su sitio web, las visitas al cual se han disparado.

Mientras, a través de la Red Mundial de Alerta y Respuesta, expertos de la Organización han ayudado a coordinar los equipos científicos y médicos que luchan contra el SRAS sobre el terreno. La OMS ha patrocinado teleconferencias clínicas en las que funcionarios de salud de diferentes países intercambiaron información. Una red de laboratorios dirigida por la OMS ha investigado el virus, $y$ redes de epidemiólogos y médicos coordinados por la Organización han proporcionado paralelamente datos sobre las modalidades de transmisión y las mejores prácticas de manejo de los pacientes. Sin la eficaz respuesta internacional articulada por la OMS y sus asociados, las pérdidas humanas y económicas causadas por el SRAS habrían sido mucho mayores.
Con el fin de estar preparados para futuros retos, acometeré de inmediato una gran ampliación y refuerzo de la Red Mundial de Alerta y Respuesta ante Brotes Epidémicos. Aumentaremos la capacidad y fortaleceremos la infraestructura en los ámbitos local, nacional y mundial para acelerar la detección y el control de las enfermedades transmisibles emergentes, nuevas o ya existentes.

2. ¿Cuáles considera que son las amenazas más graves para la salud mundial y qué va a hacer la OMS para hacerles frente?

La OMS proporciona datos, directrices y normas y asistencia técnica para ayudar a los países a identificar y afrontar sus retos prioritarios de salud. Las prioridades de los países dependen de los perfiles epidemiológicos, pero también de decisiones políticas.

Al mismo tiempo, la OMS debe hacer un uso selectivo de sus recursos limitados. En un mundo caracterizado por unas desigualdades sanitarias inadmisibles, haremos hincapié en los programas que benefician a los más pobres y a las comunidades más vulnerables.

De ahí nuestro énfasis permanente en la nutrición, por ejemplo. Por razones similares, la lucha contra las infecciones más mortíferas -VIH/SIDA, tuberculosis y malaria- debe seguir siendo una de las principales prioridades de la OMS, no sólo por la proporción de la carga mundial de morbilidad que representan tales enfermedades, sino también porque éstas castigan sobre todo a los pobres.

Hoy día, una parte creciente de la carga de morbilidad, tanto en los países de ingresos bajos como en los de ingresos altos se debe a enfermedades no 